\title{
O CENTRO ANTIGO SANGRA? UMA ANÁLISE DA QUALIDADE DA SEGURANÇA PÚBLICA NO CENTRO DA CIDADE DE SALVADOR
}

\author{
Tânia Benevides ${ }^{1}$, Lavinia Santos ${ }^{2}$, Aline Lima ${ }^{3}$, Tássio Santos ${ }^{4}$, Mauricio Freire ${ }^{5}$, Angélica \\ Santos ${ }^{6}$ e Luciana Araujo ${ }^{7}$ \\ 1,2 e 3 Universidade do Estado da Bahia (UNEB), Brasil 1tbenevides@uneb.com.br; ${ }^{2}$ laviniass22@gmail.com \\ 3paulianasf87@gmail.com \\ ${ }^{4}$ Instituto de Humanidades, Artes e Ciências Prof. Milton Santos - Universidade Federal da Bahia (UFBA) Brasil \\ tassiosantoss@hotmail.com \\ ${ }^{5}$ Universidade Federal da Bahia (UFBA), Brasil. mauriciosmith.ufba@gmail.com \\ 6y7 Universidade do Estado da Bahia (UNEB), Brasil 6aosantos@uneb.br; 7luciana.araujoc1306@gmail.com
}

\begin{abstract}
Resumo. O artigo foi desenvolvido com o objetivo de identificar quais aspectos (fatores ou elementos urbanos) influenciam a questão de segurança no centro da cidade de Salvador, a partir da caracterização e análise dos 11 bairros que integram o centro histórico. Este foi subdividido em tópicos, com ênfase em cidade, nos seus aspectos urbanos e o que tornaria uma cidade segura, perpassando pela concepção de segurança, compreendendo seus múltiplos conceitos até chegar à segurança pública e à segurança na cidade. Por fim, falamos de Salvador e seu centro, das características dos bairros que o compõem e como se dá a percepção de segurança pelos moradores dos bairros analisados. A pesquisa, no que tange à metodologia, contou com suporte de dados primários obtidos na base de dados do grupo de pesquisa QualiSalvador-UFBA, construída através de pesquisa de campo nos 163 bairros que compõem o município de Salvador, com aplicação média de cem questionários/bairro visando identificar o Índice de Qualidade Urbano Ambiental da cidade.
\end{abstract}

Palavras-chave: Cidade; Segurança; Segurança Pública; Cidade Segura; Centro.

\section{THE OLD CENTER BLEEDS? AN ANALYSIS OF THE QUALITY OF PUBLIC SAFETY IN THE CITY CENTER OF SALVADOR}

\begin{abstract}
The article was developed with the objective of identifying which aspects (factors or urban elements), influence the security issue in the centre of the city of Salvador, from the characterization and analysis of the 11 neighbourhoods that integrate the historic centre. This was subdivided into topics with an emphasis on the city in its urban aspects and what would make a city safe, running through security, understanding its multiple concepts until reaching public security and security in the city. Finally, we talk about Salvador and its centre, the characteristics of the neighbourhoods that compose it and how the residents of the analyzed neighbourhoods perceive security. The research regarding the methodology relied on the support of primary data obtained in the database of the QualiSalvador-UFBA research group built through field research in the 163 neighbourhoods that make up the municipality, with an average application of one hundred questionnaires/neighbourhood in order to identify the Urban Environmental Quality Index of the city.
\end{abstract}

Keywords: City; Security; Public Security; Safe City; Centre.

\section{INTRODUÇÃO}

A evolução humana fez com que os indivíduos se organizassem em grupos e famílias para aumentar suas chances de sobrevivência. Com isso, notaram também que, ao se estabelecer em locais fixos, poderiam montar uma série de estruturas que o permitiriam viver com mais comodidade e segurança. Tais organizações e agrupamento de indivíduos deram origens aos povoados, vilas, cidades que foram evoluindo até chegar às metrópoles 
que existem hoje. Graham (2016) chama atenção de que, até o início do século XX, cerca de $30 \%$ da população moravam, na época, em cidades, de fato, e a estimativa é de que, em 2050 , cerca de $75 \%$ da população irá residir em centros urbanos.

A concepção e construção dos espaços urbanos levaram, é claro, em conta o seu papel como centros de poder e controle militar, necessitando transformar as cidades em verdadeiras fortalezas. "Desde então, as cidades se tornaram grandes agentes centrais nas muitas formas de violência causadas pelo imperialismo capitalista" (Graham, 2016, p.60).

Salvador é uma cidade histórica e, em consequência, o seu centro carrega em si legados da história do País. Ainda assim, durante muito tempo, esta região da cidade foi negligenciada pelas autoridades responsáveis. De acordo com dados da SEI (2013), há pelo menos quatro décadas as ações e políticas públicas governamentais destinadas à expansão de Salvador não incluem o Centro Antigo, negligenciado, também, por iniciativas de ordem privada, e aquém da oferta de infraestrutura urbana moderna, refletindo um abandono do olhar para a população que reside e transita pelo local.

A partir disso, este estudo se propôs à seguinte questão de investigação: Qual a percepção dos moradores dos bairros centrais de Salvador com relação à segurança no bairro onde residem?

Como objetivo geral, busca-se identificar quais aspectos (fatores ou elementos urbanos), influenciam a questão de segurança no centro da cidade de Salvador, a partir da caracterização e análise dos 11 bairros que integram o centro histórico. Como objetivos específicos buscou-se: caracterizar Salvador, circunscrevendo o centro histórico da cidade; identificar a percepção de segurança dos moradores dos bairros que o compõem; identificar elementos urbanos característicos dos bairros estudados.

Cabe destacar que a concepção de segurança é algo intrínseco a cada indivíduo, por se tratar de um sentimento subjetivo. Se sentir seguro parte do pressuposto de que todas as condições que são fundamentais, como o bem-estar pessoal e/ou social, estejam alinhadas, e livres "[...] de fatores perturbadores que tenham a capacidade de alterar esse estado [...]" (ESG, 2009, p. 59-60). Para isso, foi realizada uma pesquisa de campo, com aplicação de, aproximadamente, cem questionários em cada um dos 11 bairros que compõem o centro de Salvador, a fim de detectar a percepção de segurança dos seus habitantes, qual o principal problema de segurança que se tem no bairro e o que, na visão de sua população residente, 
poderia trazer maior segurança ao bairro. Assim, foi possível perceber que a ideia de segurança para os moradores destes bairros difere em alguns aspectos, contudo, existem pontos que os aproximam.

Este trabalho é resultante do Projeto Qualidade do Ambiente Urbano, aprovado pelo Comitê de Ética da UFBA, que aplicou 17.000 questionários junto a residentes dos 163 bairros do município de Salvador, que envolve três Universidades - UFBA, UNEB e UEFS - e conta com financiamento da FAPESB e EMBASA.

O artigo está dividido em sete seções. A primeira aqui apresentada é a introdução, que traz os elementos delineadores da pesquisa. A segunda, terceira e quarta seções apresentam o referencial teórico utilizado para alicerçar a pesquisa de campo, abordando, dessa forma, os temas cidade, segurança e a cidade do Salvador. O percurso metodológico é apresentado na quinta seção. A sexta destina-se a apresentar a segurança no centro de Salvador, na visão de seus moradores, constituindo-se como resultados obtidos. E, por fim, na sétima e última seção são apresentadas considerações finais.

\section{CIDADE SEGURA}

As cidades já não contêm mais os sistemas fortificados como na era pré-moderna, entretanto ainda possuem as características de serem estratégicas e políticas. Segundo Gehl (2015), a sociedade está organizada em torno de várias estruturas sociais que vão definir e reforçar a sensação de segurança e pertencimento àquele local. A rápida urbanização sofrida fez com que a população urbana precisasse criar inúmeros e complexos sistemas que sustentasse a vida nas cidades.

"Ao manter o fluxo de água, lixo, energia, informação, pessoas, commodities e signos, as infraestruturas urbanas contemporâneas incorporaram sonhos iluministas de controle social e natureza. Essas infraestruturas são pré-requisitos para qualquer ideia de civilização moderna." (Graham, 2016, p.346).

A capacidade de livre trânsito dos indivíduos dentro dos territórios urbanos de forma segura é um fator fundamental para que a cidade seja funcional e adequada às pessoas. "O foco geral é manter e sustentar a visão de uma sociedade aberta, na qual as pessoas de todos os grupos socioeconômicos possam movimentar-se lado a lado, no mesmo espaço da cidade, em seus afazeres cotidianos." (GEHL, 2015, p.97). 
Existem ainda, diversos fatores que proporcionam a sensação de segurança dos transeuntes. Seres humanos são sociáveis, então, a presença de "outros," convivendo pacificamente, os desperta, ainda que subliminarmente, uma sensação maior de segurança.

Jaenisch (2010) observa que os altos níveis de violência contribuem para a proliferação dos condomínios fechados e shoppings centers. Desde então, empreendimentos desse tipo passaram a concentrar as atividades humanas - seja residencial, comercial ou de lazer.

A busca por condomínios com essas características, segundo este autor, vai além de uma preferência habitacional, mas evidencia uma necessidade coletiva de se proteger do caos urbano e do medo pela violência. "Caos, que por sua vez, é constantemente associado ao crescimento desordenado das grandes cidades, à falta de planejamento, às migrações campo-cidade, à favelização e uma série de outros processos sociais diretamente associados à presença das classes populares na cidade" (Jaenisch, 2010, p. 3).

O movimento de se conviver em locais 'fechados' causou impactos no processo de segregação social, visto que, normalmente, residem em condomínios fechados e frequentam shopping center, por exemplo, aqueles que possuem um poder aquisitivo maior. Tal movimento provocou também um esvaziamento do espaço urbano coletivo. Jaenisch (2010) ressalta que a fuga para locais privados, que era para causar proteção, acabou gerando o aumento da violência ao invés de amenizá-lo. "Não só as ruas, parques e antigos bairros centrais passaram a ser reconhecidos pelas elites urbanas como espaços perigosos e degradados (devendo portanto ser evitados)" (Jaenisch, 2010, p. 4).

\section{SEGURANÇA PÚBLICA}

Segundo o Manual Básico da Escola Superior de Guerra (ESG), "segurança é a sensação de garantia necessária e indispensável a uma sociedade e a cada um de seus integrantes, contra ameaças de qualquer natureza" (ESG, 2009, p. 59).

Pautada, assim, na adoção de políticas que possam garantir direitos aos cidadãos, sobretudo no tocante ao efetivo acompanhamento, indistintamente, do Poder Público quanto à garantia de ações estratégicas que reforcem a percepção de segurança para os cidadãos e, por conseguinte, proporcione o bem-estar para estes. O paradoxo de tudo isso é que essa segurança, muitas vezes, não é oriunda dos comandos que ostentam patentes, 
quando considerados os bairros denominados periféricos. Para essa população, o entendimento de segurança acontece de forma equivocada, pois acreditam que vêm de grupos criminosos ali estabelecidos, devido à incapacidade do Estado em combater eventos que acometem, constantemente, esses indivíduos, "situados em condições políticas, econômicas e sociais desfavoráveis" (Dias, 2010, p. 176). Este, por sua vez, é apontado, em sua maior parte, como o detentor da violência quando da resolução desses eventos por meios truculentos, em detrimento dos direitos que são assegurados aos civis, de maneira que só reforça o argumento de proteção advindas de outrem.

Essa inversão do entendimento e percepção sobre segurança faz com que as pessoas se confinem em seus lares, atrás de grades, muros, cercas elétricas e sejam vigiadas por câmeras. O que nos leva à pergunta: Quem realmente está vivendo em cárcere? Em países nórdicos, a premissa de segurança é rua iluminada e povoada, como descrito por Gehl (2015, p. 97), "Ser capaz de caminhar com segurança no espaço da cidade é pré-requisito para criar cidades funcionais e convidativas para as pessoas. Real ou percebida, a segurança é crucial para a vida na cidade."

A Segurança Pública que se configura em uma sociedade é um instrumento que garante aos indivíduos a efetiva proteção dos seus direitos individuais, e o exercício da cidadania, com a missão de promover o seu bem-estar, em sua premissa individual e social. Entretanto, há a necessidade da elaboração de um novo "Plano Nacional de Segurança Pública".

O Plano em questão admitiria que a violência no Brasil abarca todas as classes sociais (ricos e pobres) fazendo com que a situação da insegurança seja algo dividido (Brasil, PNSP, 2003 apud Dias, 2010). Ressaltando que a criminalidade atinge de maneira distinta as pessoas de acordo com a sua situação socioeconômica e cultural.

Dias (2010) ressalta que com a criação dos Estados modernos, o indivíduo passa a abrir mão do uso da violência em detrimento da garantia de segurança provida pelo Estado.

O Estado em si, deveria sempre representar o equilíbrio entre poder/força e direito. Porém, o que se nota é o uso abusivo desta condição, sobretudo nos países subdesenvolvidos, que precisam rever os critérios para o uso dela. 
Segurança "diz respeito a temas políticos cruciais, como Estado, autoridade, legitimidade, política e soberania" (Buzan, 2012, p.34). Isso posto, Segurança Pública é o Estado garantindo o direito e o dever do cidadão, para manter a ordem e a tranquilidade da sociedade. Os debates conceituais sobre segurança devem compreender, segundo o autor, um legado histórico com suas influências culturais, e os debates políticos, e não apenas como algo a ser solucionado por meios empíricos (Buzan, 2012).

Faz-se necessário destacar que a sensação e a percepção de segurança variam de acordo com o local e diversos fatores como: econômico, político, de raça, de gênero, entre outros. Os seres humanos que porventura se sentem de alguma forma inseguros, procuram se auto resguardar e proteger suas propriedades de possíveis ameaças. Gehl (2015) relata que há uma abundância de recursos que podem ser utilizados, desde arame farpado e grades, até patrulhas em áreas residenciais, guardas de segurança em frente a bancos e lojas, placas ameaçadoras, tudo como tentativas de proteção contra a invasão da propriedade privada (Gehl, 2015, p.97).

Este fenômeno também foi analisado de perto, na cidade de São Paulo, pela antropóloga Teresa Caldeira (1997), que chamou estes ambientes de "enclaves fortificados", pois "são espaços privatizados, fechados e monitorados para residência, consumo e trabalho" (Caldeira, 1997, p.155), já que, devido aos processos urbanos, as distâncias entre ricos e pobres diminuíram, eram necessários mecanismos mais óbvios e complexos para separálos.

Graham (2016) aborda o fato de que as cidades que possuem uma relativa igualdade econômica e social, como as da Europa Ocidental, tendem a oferecer uma sensação de segurança, enquanto as cidades que possuem explícitas desigualdades são marcadas pelo medo, crime, violência e militarização constante. “(...) os pobres da cidade são muitas vezes confrontados com redução nos serviços públicos, de um lado, e uma palpável demonização e criminalização do outro." (GRAHAM, 2016, p.52-53).

Portanto, segurança nas cidades não está só relacionada ao crime, mas também com a negação do outro - demonizado e criminalizado. Devido a isso, "os novos sistemas de segurança não apenas fornecem proteção do crime, mas também criam espaços segregados nos quais a prática da exclusão dos indesejáveis e a do controle dos "outros" que lá trabalham são exercidas cuidadosa e rigorosamente" (Caldeira, 1997, p.161). 


\section{SALVADOR E SEU(S) CENTRO(S): BAIRROS E SUAS CARACTERÍSTICAS NO CONJUNTO}

Basta olhar o mapa de Salvador para constatar que os centros - histórico e antigo - da cidade não ficam localizadas no centro geográfico, no lugar deles temos uma região conhecida como "miolo", composta por bairros como Cabula, São Gonçalo, Resgate, entre outros, "ocupado pela implantação de conjuntos residenciais para a "classe média baixa" na fase áurea da produção imobiliária, através do Sistema Financeiro de Habitação, tendo a sua expansão continuada por loteamentos populares e sucessivas invasões coletivas, com uma disponibilidade de equipamentos e serviços bastante restrita (Carvalho \& Pereira, 2008, p. 86).

Acontece que essa definição é a oposta da que se pensa ao falar e ouvir a palavra centro. $O$ contrário também acontece, a Orla Marítima, vista como um lugar rico socioeconomicamente, não fica em uma região central. Dado isso, vale reflexões históricas e filosóficas: Como e quando um centro é feito? Quem define o que é centro e o que é periferia? "Central e periférico em relação a quê? A quem?" (Serpa, 2002, p.295).

Historicamente, o Centro de Salvador exerceu funções "muito representativas quer da vida urbana, quer da vida regional" (Santos, 2008, p. 69), apresentando, primeiramente e estrategicamente, uma função portuária, já que "era preciso construir Salvador bem perto do mar para facilitar as comunicações com a metrópole", bem como, também, era essencial "edificá-la sobre a escarpa, sobre o dorso das colinas, para defendê-la dos possíveis ataques, seja de estrangeiros, pelo lado do mar, seja dos índios, vindos do interior" (Santos, 2008, p. 103).

Esta foi "a condição necessária" para realização de outras funções - como administrativas, comerciais, bancárias, industriais e artesanais - e aspectos - como centro histórico, religioso, administrativo, turístico e de negócios.

Apesar de algumas funções e aspectos destes ainda se conservarem atualmente, o Centro Histórico da cidade de Salvador perdeu consideravelmente seu poderio e influência sobre o resto da metrópole. Principalmente, com o surgimento de outro centro. Carvalho e Pereira (2008) relatam que nos anos de 1980 o novo centro urbano de Salvador foi consolidado a partir do impulsionamento dado pela realização de grandes empreendimentos públicos e privados, realizados na década de setenta. São eles: Av. Paralela, Centro Administrativo da 
Bahia, nova Estação Rodoviária e Shopping Iguatemi. "Essa nova centralidade não apenas direcionou a expansão urbana no sentido da orla norte, como teve impacto na dinâmica do centro tradicional na área antiga da cidade, contribuindo para o seu gradativo esvaziamento". (Carvalho \& Pereira, 2008, p.85).

Dada a importância do Centro Histórico de Salvador, surgiram em seu entorno outros bairros que ficaram conhecidos como Centro Antigo de Salvador e que serão analisados neste trabalho. São eles: Centro (2 de Julho e Centro), Barris, Tororó, Nazaré, Saúde, Barbalho, Macaúbas, Comércio e Santo Antônio Além do Carmo, bem como o próprio Centro Histórico. Apesar das suas similaridades, os bairros em questão trazem particularidades que marcaram sua trajetória. Os mais próximos do Centro Histórico, (Santo Antônio, Comércio, Saúde, Centro e Tororó), embora abriguem residências, carregam na sua essência grande potencial turístico, por conta da sua trajetória histórica, com ênfase na religiosidade, notadamente por suas suntuosas igrejas e espaços culturais.

Na região é possível encontrar acomodações para todos os bolsos, em hotéis 4 estrelas ou em simples e aconchegantes pousadas, além de inúmeras opções de bares e restaurantes, permitindo aos visitantes uma fantástica viagem gastronômica por sabores que vão da culinária local à cozinha internacional. Os demais (Barbalho, Barris, Dois de Julho, Macaúbas e Nazaré), apresentam maior concentração de moradias, mesclada por igrejas, escolas, bibliotecas, hospitais e delegacias. Há também uma variação no número de habitantes onde Macaúbas com menor quantitativo apresenta cerca de 2.006 moradores, enquanto o Centro com maior número tem em torno de 15.688 .

Caracterizado por abranger bairros os quais não possuem 'vida cotidiana,' devido à ausência de multifuncionalidades, o processo de depreciação conjunta da região opera como normalidade no contexto de gestão da Cidade de Salvador, que, após paliativas intervenções, não conseguiu reverter o quadro de vulnerabilidade e periferização destes territórios.

Justamente pelo tecido urbano do Centro Antigo de Salvador (CAS) e sua redondeza ser considerado "compacto, relativamente homogêneo, e não ter um crescimento expressivo da população, que é composto, predominantemente, pelos setores médios" (Carvalho \& Pereira, 2008, p. 101), que foi definido como "cidade tradicional" e apresenta configurações socioculturais e físico ambientais totalmente diferentes da "cidade moderna", definida como lugar onde há predominância de "produção de novas habitações e centros de consumo e 
serviços, construídos dentro de padrões arquitetônicos e urbanísticos elevados" e da "cidade precária, "ocupada, predominantemente, pelos setores populares, o tecido urbano se caracteriza pela dispersão e pela contínua expansão com o acréscimo de habitações precárias, em grande parte, autoconstruídas sem obedecer a padrões arquitetônicos e urbanísticos". (Carvalho \& Pereira, 2008, p. 101)

A divisão entre a Cidade Alta e a Cidade Baixa constitui um fator característico da paisagem central da cidade do Salvador. Divisão a qual é marcada por antagonismos e contrastes urbanísticos, advindos, sobretudo, perante os novos modelos de expansão urbana, calcados pela lógica industrial-metropolitana, marcada pela construção de uma nova frente de expansão urbana para a cidade. Falar sobre o Centro Antigo é falar sobre a preciosidade do patrimônio histórico, artístico e cultural, ao qual este local abrange, onde vivem cerca de 77,7 mil habitantes (SEI, 2013), sendo um dos principais pontos atrativos de Salvador no mercado turístico nacional e internacional. Para tanto, denota-se a necessidade de caracterizá-lo urbanisticamente, visto que, de maneira geral, o Centro Antigo é um território que apresenta pequena concentração de moradores em decorrência do tipo de ocupação, com predomínio de casas e prédios de poucos andares.

A consolidação do padrão periférico de apropriação do Centro da Cidade de Salvador se dá em diferentes tendências, com o esvaziamento demográfico e econômico do centro, cuja degradação sobrevém a partir do paradoxo entre cidade "moderna" e "precária," reproduzindo a desigualdade em razão de seu desenvolvimento privilegiado, em detrimento de outros pontos da cidade. Há no centro uma distribuição desigual de investimentos geradores do bem-estar social urbano, deflagrando intempéries seletivas promotoras de segregação, como bem retratada na música "Duas Cidades" do grupo Baianasystem, uma banda musical da cidade de Salvador: "Divi-divi-divi-dividir Salvador / Diz em que cidade que você se encaixa / Cidade Alta / Cidade Baixa / Diz em que cidade que você / Ãn, ãn, Salvador" (Baianasystem, 2020, on line).

Após sucessivos programas - tanto de revitalização, quanto de reabilitação - o Centro Antigo da Cidade de Salvador ganhou um novo rosto, afinal, ambos contribuíram para o reaparecimento de atividades e consumidores com rendas mais altas e maior acesso ao consumo. Para isso, alguns antigos moradores tradicionais sofreram um processo de gentrificação, não tradicional, mas "(re)apropriação dos espaços privados e públicos" por turistas e consumidores de camadas sociais superiores" (Mourad, 2011, p. 101). Como tais 
moradores têm cor e classe, os movimentos sociais que ocupam a região chamam tal processo de "faxina étnica".

O poder público, que deveria agir visando garantir o direito de todos, age em benefícios de interesses de poucos. Este processo foi chamado de "privatização da gestão urbana" por Carvalho e Pereira (2013). Os mesmos movimentos denunciam este processo com gritos e pinchos de protesto.

O caráter histórico e plural do fenômeno da segregação vem sendo acentuado com a difusão do paradigma das cidades globais associados à privatização dos espaços públicos, fatores que incidem vorazmente na reprodução de auto segregação e periferização, homogeneizando espaços e expulsando grupos nativos de seus locais de origem, como de praxe na história do processo de urbanização da cidade, sobretudo no Centro de Salvador, enviesado por uma política de reabilitação que reforça ações de iniciativa privada atinentes aos componentes necessários para que a gentrificação ocorra voltadas para o mercado em busca de consumidores de classe média e alta, em detrimento dos moradores tradicionais pertencentes a classes sociais desfavorecidas (Mourad, 2011).

\section{METODOLOGIA}

Em relação ao percurso metodológico, fez-se necessário o planejamento do método a ser utilizado nesta pesquisa. Minayo (2011, p.14) diz que a metodologia é o caminho do pensamento e a prática exercida na abordagem da realidade. "[...] a metodologia inclui simultaneamente a teoria da abordagem (o método), os instrumentos de operacionalização do conhecimento (as técnicas) e a criatividade do pesquisador (sua experiência, sua capacidade pessoal e sustentabilidade)". Assim, a pesquisa foi desenvolvida, inicialmente, através de levantamento de dados secundários, portanto, bibliográficos, tendo como referência autores e estudiosos com publicações sobre a temática Segurança, Segurança Pública, Cidades e Bairros, caracterizando o Centro de Salvador, sobretudo os 11 bairros analisados neste estudo.

Os dados primários utilizados são do Projeto Qualidade do Ambiente Urbano de Salvador, QUALISalvador, que tem como objeto de estudo a realidade urbano ambiental de Salvador, buscando produzir e difundir conhecimento sobre a referida realidade, na escala intraurbana. As principais categorias de análise utilizadas são: qualidade das águas; adequação ambiental; acesso aos serviços de saneamento ambiental; acesso aos serviços 
de consumo coletivo; condições de saúde e segurança pública; inserção produtiva; vulnerabilidade; percepção da qualidade do ambiente urbano e participação cidadã. O presente projeto articula em rede instituições no âmbito da universidade, órgãos públicos, alunos de graduação e pós-graduação, pesquisadores, professores e gestores públicos e sociais que têm na problemática urbana e ambiental seu objeto de estudo e de intervenção. Para o seu cumprimento está sendo utilizada a metodologia da triangulação, de modo a estabelecer uma relação de complementaridade entre os métodos quantitativos e qualitativos, visando a produção dos seguintes resultados: análise da qualidade urbano ambiental de Salvador na escala intra-urbana (por bacia hidrográfica, de drenagem e bairro; consolidação da Rede QUALISalvador; instituição de mecanismos de informação e comunicação no âmbito da Rede QUALISalvador; produção do Índice de Qualidade Urbano Ambiental QUALISalvador; criação do Sistema para cálculo do Índice de Qualidade UrbanoAmbiental de Salvador QUALISalvador em software livre; realização de reuniões e seminários abertos para discussão dos resultados do trabalho realizados; fundamentação de teses, dissertações, monografias, publicações acadêmicas e científicas produzidas pelos e com a participação de estudantes de graduação e pós-graduação; realização de trabalhos científicos, técnicos e subsídio para formulação e implementação de política urbana e ambiental realizados (Qualisalvador, 2020).

No Projeto Qualidade Urbano-Ambiental de Salvador, QUALISalvador, há um subgrupo denominado QualiSeg, voltado à investigação das questões de segurança do referido Projeto. Assim, os componentes do QualiSeg, autores deste artigo, recortaram os dados do centro de Salvador a fim de produzir uma análise específica de segurança na região. Foram utilizados neste trabalho dados referentes à percepção dos moradores dos bairros supramencionados, a partir da aplicação de 1.022 questionários, nos anos de 2018 e 2019. Os domicílios de aplicação do questionário foram escolhidos segundo amostra aleatória estratificada com reposição, definida através da utilização de método estatístico.

Deste modo, sempre que era necessário substituir um domicílio sorteado, o pesquisador de campo se posicionava em frente ao domicílio amostrado e depois se dirigia ao primeiro domicílio do seu lado direito, para desta forma garantir a aleatoriedade e legitimidade do método.

Os dados coletados foram tabulados em um banco de dados do grupo de pesquisa e analisados pelos autores deste artigo. Para a análise ora apresentada, optou-se pela análise 
qualitativa, uma vez que Minayo (2011) afirma que o objeto das ciências sociais é, essencialmente, qualitativo, já que a realidade social é mais rica que qualquer teoria, pensamento ou discurso que se possa elaborar sobre ela. Essa escolha deve-se ao fato deste trabalho analisar o resultado na percepção dos moradores de um conjunto de bairros da cidade do Salvador, no estado da Bahia. Trata-se de uma representação social permeada de símbolos, significados e subjetividades, sendo assim um nível de realidade que, embora esteja quantificado em um banco de dados, pode ser analisado qualitativamente a partir da interpretação dos autores deste artigo, que viveram a fase de coleta de dados, vivenciando, no período, a realidade de cada um dos bairros. Por fim, esta pesquisa deverá produzir um conhecimento sistemático, crítico e inovador sobre a realidade urbano-ambiental de uma cidade que se insere de forma subordinada no atual processo de produção e reprodução capitalista (Qualisalvador, 2020).

\section{SEGURANÇA NO CENTRO DE SALVADOR NA VISÃO DE SEUS MORADORES}

Nessa seção, pode-se observar os dados obtidos a partir da pesquisa de campo. Para isso, foram feitas aos entrevistados 3 perguntas em relação a segurança, quais sejam: Você se sente seguro no seu bairro? Em sua opinião qual o principal problema de segurança no bairro? O que poderia trazer segurança para seu bairro? O locus desta pesquisa é o centro de Salvador, especificamente, os bairros do Barbalho, Barris, Centro, Dois de Julho, Centro Histórico, Comércio, Macaubas, Nazaré, Santo Antônio, Saúde e Tororó.

Com relação à primeira pergunta "Você se sente Seguro no seu bairro?", verificou-se que, nos dados analisados nos onze (11) bairros, em apenas dois (2) deles (Comércio e Saúde), mais de cinquenta por cento $(50 \%)$ dos entrevistados se sentem seguros a qualquer dia e horário, ficando os outros nove (9) bairros, Barbalho, Barris, Centro, Centro/Dois de Julho, Centro Histórico, Macaúbas, Nazaré, Santo Antônio e Tororó, oscilando entre vinte e um por cento $(21 \%)$ e quarenta e nove por cento $(49 \%)$ dos respondentes.

Os que responderam mais ou menos, apenas durante o dia, oscilam entre dezessete e quarenta e dois por cento (17\% e $42 \%$ ), e os que não se sentem seguros variam de catorze a trinta e nove por cento (14\% a 39\%). A alternativa "Outros" aparece em quatro (4) bairros: Barris, Centro, Centro/Dois de Julho e Centro Histórico, com apenas um por cento (1\%) das respostas em cada. No bairro do Comércio, três por cento (3\%) dos entrevistados declararam não saber responder, seguido por um por cento (1\%) no bairro da Saúde. 
Apenas um (1) morador do bairro Centro/Dois de Julho (1\%) alegou não ter informação a respeito.

Quando perguntados "Em sua opinião qual o principal problema de segurança no bairro?, pode-se perceber, em dez deles, que mais de cinquenta por cento dos entrevistados apontaram "roubo a transeuntes" como principal problema de segurança, exceto no bairro do comércio onde apenas $27 \%$ dos entrevistados apontaram esta modalidade. Em segundo lugar aparece a opção "não tem problema de segurança", seguido de "roubo a casa comercial", "roubo a veículo" e "roubo a residência".

É interessante ressaltar que o bairro do Comércio, apresentado como um dos mais seguros em relação aos outros pesquisados, foi o que apontou o maior índice de que "não há problema de segurança". Isso pode se dar em razão do fato de que este bairro, em específico, possui característica comercial acentuada, já que nele estão instaladas instituições empresariais de diferentes tipos, tais como faculdades, bancos e prédios empresariais que geram movimentação intensa tanto durante o dia, quanto à noite.

Esta realidade remete à fala de Gehl (2015), segundo a qual a presença de outras pessoas em movimento e/ou realizando atividades rotineiras, normalmente, transmite a sensação de segurança.

Em contrapartida, o bairro do Centro, que também apresenta característica comercial forte não mais de centro empresarial, e sim de comércio de rua (formais e informais) - foi apontado nesta pesquisa como um dos mais inseguros e que apresentou o maior percentual de roubo a transeunte, dentre os bairros analisados. Dessa forma, percebe-se que somente a presença de outras pessoas não é garantia suficiente para a segurança de um local, outros fatores também são necessários, tal qual abordado na questão seguinte.

Quando perguntados sobre "o que poderia trazer segurança para seu bairro", a avaliação dos dados permitiu concluir que em seis dos bairros avaliados (Barbalho, Barris, Centro, Macaúbas, Nazaré e Tororó) mais de $20 \%$ dos entrevistados apontam policiamento ostensivo como principal fator que pode trazer segurança, seguido por ronda no bairro, apontado por mais de 15\% dos entrevistados em sete bairros (Barbalho, Barris, Centro, Macaúbas, Nazaré, Santo Antônio, Saúde e Tororó). 
Em menor escala, foram identificados os itens Investimentos Sócio Educacionais, Efetivo policial, Ter uma delegacia/posto policial. É importante ressaltar que as alternativas Policiamento Ostensivo, Efetivo Policial, Ronda no Bairro, Ter uma delegacia/posto policial, Incursões no reduto dos crimes e Intensificar blitz nas ruas foram agregadas como uma única, denominada Policiamento, bem como Qualificação dos policiais, Valorização e qualificação dos policiais, Investimentos em equipamentos e tecnologia e Combate a corrupção policial foram agregadas como Qualificação dos policiais.

\section{CONSIDERAÇÕES FINAIS}

Dadas as análises, compreende-se a imprescindibilidade do questionamento perante o termo segurança e como este opera de diferentes formas atinentes aos distintos recortes socioeconômicos na cidade de Salvador, sendo possível fomentar a discussão perante a existência de dilemas de segurança para os moradores dos bairros centrais.

A Política Nacional de Segurança Pública, articulada juridicamente conforme dispõe a Lei no 11.530/07, que instituiu o Programa Nacional de Segurança Pública como Cidadania, cristaliza-se de forma incapaz de lidar com as dinâmicas de insegurança pública, como destacado nas respostas dos moradores entrevistados no Centro da cidade de Salvador.

Diante deste cenário, percebe-se que a cidade vive focos de violência nos principais bairros do centro urbano, perpetradas por uma lógica neoliberal e capitalista que provém de uma intermitente construção de muros físicos e simbólicos no Centro de Salvador. Como bem observado por Buzan (2012), cidadãos submetem-se aos procedimentos globais das cidades sitiadas, as quais por sua vez retroalimentam uma relação de cativo para com seus moradores, reféns dos dispositivos que produzem sensações de segurança.

Questiona-se, desta forma, o papel da política e sua respectiva atuação pragmática, entendendo-se que a segurança pública deve ser vista como uma articulação de várias políticas públicas/sociais, inclusive urbanísticas, para que a população se sinta convidada a frequentar e transformar positivamente o seu próprio espaço urbano. Dado que grande parte dos entrevistados afirmou não se sentir seguro no próprio bairro em que vive, denota-se a importância da criticidade perante às atuais políticas públicas e se estas estão de fato atreladas ao enfrentamento de problemas públicos concretos (Secchi, 2017) e comprometem-se com a ineficiência, ineficácia e descontinuidade ou com a enfática resolução dos graves problemas sociais enfrentados pela população do Centro de Salvador, 
pois o cidadão deve se sentir seguro e livre para ocupar o espaço urbano, que por sua vez é transformado pelas relações convergentes e divergentes de produção desses mesmos territórios.

Os onze bairros que dão forma ao Centro Antigo de Salvador, apesar de formarem uma unidade, são diversos e diferentes entre si.

Quando se tratou da sensação de Segurança, nota-se que, aproximadamente, 39\% dos entrevistados se sentem seguros e $31 \%$ dos entrevistados se sentem seguros apenas de dia, revelando a importância que os fatores lluminação e Ocupação do Espaço Urbano podem ter. Apesar disso, quando se tratou dos problemas existentes, na maioria quase que absoluta dos bairros (10) aparece roubo a transeunte. Perguntados sobre a solução para os problemas de segurança, houve uma predominância de respostas referentes à Policiamento, tais como Policiamento Ostensivo (25\%) e Ronda Policial (17\%).

Além disso, ressalta-se que as etapas de coleta de dados e metodologia foram importantes à medida que possibilitam identificar dados relevantes à formulação de políticas públicas, legitimando uma relação simbiótica, já que a população é o centro e alvo de tais políticas.

\section{REFERÊNCIAS}

Buzan, B. A evolução dos estudos de segurança internacional. São Paulo: Ed. Unesp, 2012.

Caldeira, T. Enclaves fortificados: a nova segregação urbana. Novos Estudos CEBRAP N. ${ }^{4}$ 47, mar. 1997.

Baianasystem. Disponível em: http://baianasystem.com.br/duas-cidades-letras/\#05.

Carvalho, I. M.; Pereira, G. C. A cidade como Negócio. EURE. vol. 39 , no 118, set. 2013.

Carvalho, I. M.; Pereira, G. C. As "cidades” de Salvador. In: Carvalho, Inaiá M.; Pereira, Gilberto C. (Org.) Como anda Salvador? 2. ed. Salvador: EDUFBA, 2008.

Dias, L. L. A política de Segurança Pública entre o monopólio legítimo da força e os direitos humanos: a experiência da Paraíba no pós 1988. 2010. Tese (Doutorado). Programa de Pós-Graduação em Serviço Social, Universidade Federal de Pernambuco, Recife, 2010.

Escola Superior de Guerra (BRASIL). Fundamentos da Escola Superior de Guerra, Rio de Janeiro: ESG, v. 1, 66 p. 2009.

Gehl, J. Cidades para pessoas; tradução Anita Di Marco. 2 ed. São Paulo: Perspectiva, 2015.

Graham, S. Cidade sitiadas: o novo urbanismo militar. São Paulo: Boitempo, 2016.

Jaenisch, S. T. Entre cercas, muros e alarmes: sobre o medo da violência urbana e a criação de espaços segregados na cidade. In: SIMPÓSIO INTERNACIONAL DIÁLOGOS DA CONTEMPORANEIDADE, 2. Porto Alegre, 2010. Anais. Lajeado, RS.

Minayo, M. C. .S.. Pesquisa social: teoria, método e criatividade. 26.ed. Petrópolis, RJ: Vozes, 2011. 
Mourad, L. N. O processo de gentrificação do Centro Antigo de Salvador 2000 a 2010. Tese (Doutorado em Arquitetura e Urbanismo). Universidade Federal da Bahia, 2011.

Sales, D. A arquitetura soteropolitana e o espírito do lugar. Disponível em: https://www.vitruvius.com.br/revistas/read/minhacidade/18.211/6870\%3E.

Santos, E.; Pinho, J. A. de.; Moraes, L. R. S.\& Fischer, T. (org.). O caminho das águas em salvador: Bacias Hidrográficas, Bairros e Fontes. Salvador: CIAGS/UFBA; SEMA, 2010.

Santos, M. O centro da cidade de Salvador. 2. ed. Salvador: EDUFBA, 2008.

Secchi, L. Análise de Políticas Públicas: diagnóstico de problemas, recomendação de soluções. São Paulo: Cengage Learning, 2017.

SEI. Superintendência de Estudos Econômicos e Sociais da Bahia. CAS - Centro Antigo de Salvador: território de referência. SEI, 2013. Disponível em: https://www.sei.ba.gov.br/images/publicacoes/download/cas/cas.pdf.

Serpa, A. Margens de Salvador: a Produção do Espaço Periférico Metropolitano. In: LIMA, Paulo Costa et al (Org.). Quem faz Salvador? Salvador: UFBA, 2002. 